\title{
Cardiovascular Evaluation in Bitches in Oestrus, Pregnancy and Puerperium*
}

\author{
Mayara Cristini Ferreira Aguiar', Karina Preising Aptekmann', Leandro Egert', \\ Afonso Cassa Reis', Ana Paula Madureira² \& Márcio Paiva Barcellos ${ }^{3}$
}

\begin{abstract}
Background: Pregnancy may change maternal hemodynamic, which is considered a physiological mechanism for adaptation. Cardiac output tends to be influenced by reductions in vascular resistance and increases in uterine vasculature, as well as reduced autonomic tone combined with gestational physiological anaemia and increased blood volume due to increased plasma volume and hormonal mechanisms. In bitches, few studies have been conducted investigating the changes of the system and the clinical implications for the mother and foetuses due to poor cardiac adaptation during pregnancy.

Materials, Methods \& Results: Systolic blood pressure (SBP), electrocardiographic and Doppler echocardiographic measurements and serum sodium $(\mathrm{Na})$, potassium $(\mathrm{K})$, calcium $(\mathrm{Ca})$ and phosphorus $(\mathrm{P})$ levels were evaluated in six bitches of reproductive age. An evaluation was performed in oestrus (M0), followed by evaluations at 25 (M1), 45 (M2), and 60 days (M3) after the last natural or artificial insemination and 15 days after delivery (M4). For the statistical analysis, the means, medians and the standard deviation were calculated. The data were analysed using ANOVA and the Tukey test, with significance level of 5\%. A descriptive analysis was performed for color Doppler in echocardiogram evaluation, cardiac axis and rhythm in electrocardiogram evaluation. In the electrolytic evaluation, significant differences were found only in the serum levels of Na, noticed as a reduction in M0-M1 and M3-M2 and an increase in M1-M2 and M3-M4. No significant differences were observed in the SBP, although there was a tendency to SBP reduction. ECG parameters were not significantly different, with no rhythm or conduction disturbances. There was not a significant difference in HR. Four animals $(66.6 \%)$ had axis deviation to the right when comparing the oestrous phase with the final quarter of pregnancy. The echocardiographic parameters did not show significant changes.

Discussion: The reduction observed in Na can occur by salt depletion, by dilutional or metabolic mechanisms. In contrast, the elevation in Na concentration could occur as a result of fluid and electrolyte retention by kidneys during gestation. The absence of electrocardiographic changes may be justified by the stability of mean serum potassium concentrations. An increase in HR five days before the expected calving time, demonstrating the maximum cardiac activity in this gestational phase, is related by other authors, therefore, in the present study, the absence of significant change in HR can be explained by the period in which the data collection was performed, 45 days of gestation, being therefore prior to the period of greatest HR. The cardiac axis deviation can be explained by the distension of the gravid uterus that cause compression of the adjacent organs, leading to diaphragmatic compression and consequent repositioning of the thoracic structures. A tendency to SBP reduction observed is directly influenced by peripheral vascular resistance and cardiac output that occur during pregnancy. Although the echocardiographic findings did not show changes, it is suggested that there are changes related to increased blood volume in pregnancy to provide an appropriate blood flow to the conceptus. It was concluded that pregnancy and the postpartum period in bitches did not cause changes in electrolytes levels, SBP values, echocardiographic and electrocardiographic parameters as compared to values obtained during oestrus.
\end{abstract}

Keywords: echocardiogram, electrocardiogram, pregnancy, electrolytes. 


\section{INTRODUCTION}

It is thought that pregnancy changes maternal hemodynamics, which may cause clinical signs that resemble heart diseases [13]. Thus, the addition of cardiovascular evaluation to the prenatal testing of bitches aims to obtain information about physiological changes or detect diseases that may manifest or start due to the greater effort of the heart muscles and changes in systemic systolic blood pressure (SBP) [1].

Cardiac output tends to be influenced by reductions in peripheral vascular resistance and increases in uterine vasculature, as well as reduced autonomic tone associated with mild gestational physiological anaemia and increased blood volume. These can lead to cardiac morphological alterations, such as myocardial hypertrophy and increased heart chambers [18].

Most reports of cardiac abnormalities are on women and rats and are considered to be physiological mechanisms for adaptation of the cardiovascular system to volume overload caused by pregnancy. In bitches, few studies have been conducted investigating the changes suffered by the system and the clinical implications for pregnant animals and foetuses due to poor cardiac adaptation during pregnancy [4,5]. Therefore, the aim of this study was to investigate cardiovascular and electrolyte changes in bitches during oestrus and pregnancy stages, and the early postpartum period.

\section{MATERIALS AND METHODS}

\section{Animals}

Six bitches suitable for reproduction were included, with a mean age of $1.8 \pm 0.72$ years (between 1 and 2 years and 3 months) and mean weight of 10.7 $\mathrm{kg} \pm 8.9$ (between 2.3 and $24 \mathrm{~kg}$ ). The dogs were of the following breeds: Yorkshire terrier, Golden retriever, French bulldog, German shepherd, Maltese and Pug. Each owner was informed about the study and signed a free consent form.

For animal selection, there was a complete physical examination, blood collection for conducting blood count and biochemical testing (urea, creatinine, alanine aminotransferase (ALT), alkaline phosphatase (ALP), total protein and albumin). Cardiovascular evaluation was performed by electrocardiographic, echocardiographic and systemic SBP measurements. Only animals having all parameters within normal limits for the species were included in the study.
Study design

Cardiovascular examinations, including electrocardiogram (ECG), echocardiogram (ECHO) and SBP, and electrolytes evaluation (sodium (Na), potassium $(\mathrm{K})$, calcium $(\mathrm{Ca})$ and phosphorus $(\mathrm{P})$ were performed at five different time points of the study. M0 was considered the first moment when the bitches expressed oestrus, as determined by assessing behavioural changes and performing vaginal cytology. The other time points were at 25 (M1), 45 (M2) and 60 days after the last natural or artificial insemination (M3) and 15 days after delivery (M4). Abdominal ultrasonography were performed just to monitor the pregnancy (M0-M3) and uterine involution (M4) after delivery.

\section{Data collection}

To determine the serum levels of $\mathrm{Na}, \mathrm{K}, \mathrm{Ca}$ and $\mathrm{P}$, individual samples of $10 \mathrm{~mL}$ of whole blood were collected by jugular vein puncture and centrifuged to obtain the serum. Serum samples were put into eppendorf tubes and kept refrigerated at $-80^{\circ} \mathrm{C}$ until the time of dosing. The flame photometry technique was carried out. The reference ranges were as those described at the literature [6].

Electrocardiographic examinations were performed using a computerized portable electrocardiogram machine (TEB-ECG-PC) ${ }^{1}$. The animals were positioned in right lateral decubitus, and the electrodes were positioned according to the recommendations [20]. The electrocardiographic monitoring lasted an average of one minute, and the stroke was filed in the computer and analysed later. Bipolar (I, II, III) and unipolar derivations (aVR, aVF, aVL) were evaluated. Heart rate (HR), rhythm, cardiac axis, duration in milliseconds (ms) of P, PR, QRS and QT and amplitudes in millivolts $(\mathrm{mV})$ of $\mathrm{P}, \mathrm{Q}, \mathrm{R}, \mathrm{T}$, and $\mathrm{ST}$ segment deviation from the baseline were determined according to the literature [20].

To perform the echocardiographic examination, an ultrasound device (Mylab TM 30VET Gold) ${ }^{2}$, with two sectoral transducers at a frequency of 1 to 4 $\mathrm{MHz}$ was used. Longitudinal and transverse cuts of the heart were performed according to recommendations by Boon [7]. The echocardiographic parameters for each dog were indexed by dividing the echocardiographic measurements by the body surface area of each individual [7] and were also performed by a single examiner. 
In the right parasternal window on the transverse axis, the following parameters were evaluated in the $\mathrm{M}$ mode: thickness of the interventricular septum in diastole (IVSd) and systole (IVSs), left ventricular internal diameter (LVD) in diastole (LVDd) and systole (LVDs), left ventricular free wall in diastole (LVWd) and systole (LVWs), heart rate (HR) and E point to septal separation (EPSS). The shortening fraction (FS) and left ventricular ejection fraction $(\mathrm{EF})$ were calculated automatically by the equipment; and in mode B: diameter of left atrium (LA) and aorta (Ao), and the left atrial aortic root ratio (LA/Ao) was determined. In the cardiac base image, spectral Doppler evaluation of the maximum pulmonary flow velocity (Ap-Vmax) and color Doppler of the pulmonary artery were performed [7].

In the left parasternal window, images were obtained in the apical windows, where the spectral Doppler values of maximum aortic flow velocity (Ao-Vmax) were obtained. It was made a subjective evaluation of the cardiac chambers and movement of the valve leaflets. It was also evaluated color and spectral Doppler for values of mitral flow - wave A (Mitral A) and wave E (Mitral E).

SBP was obtained by a non-invasive method with vascular Doppler ultrasound (DV 610V Medmega) $)^{3}$ on the palmar metacarpal region of the left forelimb with the animal in right lateral decubitus. He was placed into the cuff (the width corresponding to $40 \%$ of the toracic member's circumference) on the proximal third of the radioulnar region. After obtaining the appropriate pulse signals, the cuff was inflated to approximately $30 \mathrm{mmHg}$ higher than the pressure required to obliterate the audible pulse signal and then slowly deflated. The systolic pressure was determined at the time the pulse signal became audible again. For a better standardization of the results, five SBP measurements were performed on each animal, and the average of each measurement was used.

\section{Statistical analysis}

For the statistical analysis, the data were initially submitted to descriptive analysis to obtain the means, medians and the standard deviation. The data were then submitted to the Shapiro-Wilk normality test, followed by the comparison between the time points using ANOVA and the Tukey test [8]. The percentage differences between the values were obtained through transformation by the formula [Final Value - Initial Value / Initial Value] x 100. All tests were performed with significance level of 5\%. The IBM SPSS Statistics program
(2010) was used. A descriptive analysis was performed for color Doppler in echocardiogram evaluation, cardiac axis and rhythm in electrocardiogram evaluation and the individual values were evaluated in according to the reference ranges for dogs in general [7].

\section{RESULTS}

No bitch presented perinatal or gestational complications. There were no significant cardiovascular changes during evaluations performed during oestrus, pregnancy and the puerperal period.

In the electrolytic evaluation, a significant difference was only found in the average values of $\mathrm{Na}(P<$ $0.05)$. There was a reduction in M0-M1 and M3-M2 and an increase in M1-M2 and M3-M4 (Table 1). No other alteration in electrolyte concentration was observed.

No dog in this study presented rhythm or conduction disturbance in the electrocardiographic exam. All dogs presented sinus rhythm, except one dog that presented respiratory sinus arrhythmia in M4. There was no significant difference $(P>0.05)$ in the electrocardiographic parameters and HR (Table 2). Although no significant difference was observed in the evaluation of the cardiac axis, four animals $(66.6 \%)$ had axis deviation to the right when comparing the oestrous phase with the final quarter of pregnancy (M2) [Table 2], but two of these animals still had values consistent with normal for the species [20].

There was no significant difference $(P>0.05)$ between mean values of SBP, although there was a tendency to decrease pressure, as showed in Figure 1. The data obtained by echocardiography showed no significant difference between the assessed time points (Table 3).

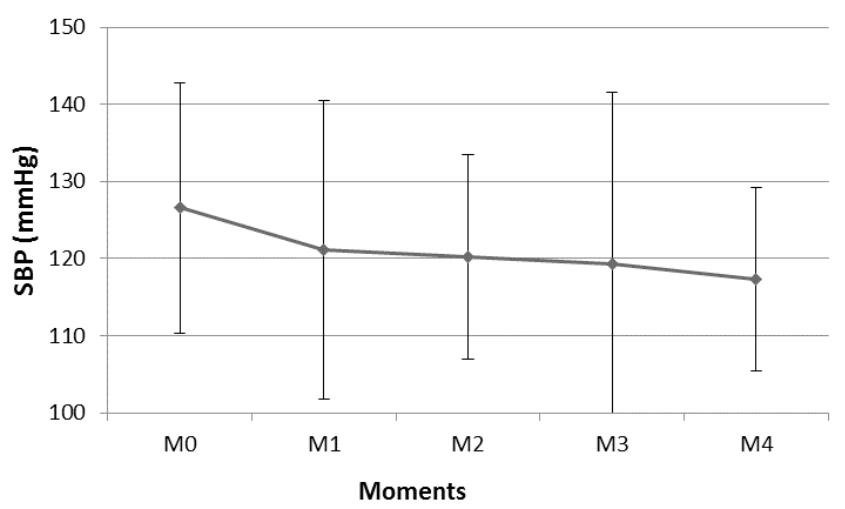

Figure 1. Mean and standard deviation (SD) of systolic blood pressure (SBP) (mmHg) of six bitches at different experimental times during oestrus, pregnancy and the puerperal phase. M0: oestrus; M1: 25 days after the last natural or artificial insemination; M2: 45 days after the last natural or artificial insemination; M3: 60 days after the last natural or artificial insemination; M4: 15 days after delivery. $(P>0.05$; Tukey test). 
Table 1. Mean and standard deviation (SD) values for sodium $(\mathrm{Na})$, potassium $(\mathrm{K})$, calcium $(\mathrm{Ca})$ and phosphorus $(\mathrm{P})$ of six bitches at different experimental times during oestrous, pregnancy and the postpartum period.

\begin{tabular}{ccccc}
\hline & \multicolumn{4}{c}{ Electrolytes $($ mean* $\pm \mathrm{SD})$} \\
\hline Moment & $\mathrm{Na}^{1}(\mathrm{mg} / \mathrm{dL})$ & $\mathrm{K}^{2}(\mathrm{mEq} / \mathrm{L})$ & $\mathrm{Ca}^{3}(\mathrm{mg} / \mathrm{dL})$ & $\mathrm{P}^{4}(\mathrm{mg} / \mathrm{dL})$ \\
\hline M0 & $145.8^{\mathrm{a}} \pm 4.35$ & $4.3^{\mathrm{a}} \pm 0.42$ & $9.7^{\mathrm{a}} \pm 0.65$ & $4.6^{\mathrm{a}} \pm 1.03$ \\
M1 & $138.0^{\mathrm{b}} \pm 6.13$ & $4.1^{\mathrm{a}} \pm 0.38$ & $9.5^{\mathrm{a}} \pm 1.10$ & $4.9^{\mathrm{a}} \pm 0.53$ \\
M2 & $145.7^{\mathrm{ac}} \pm 3.07$ & $4.3^{\mathrm{a}} \pm 0.65$ & $9.3^{\mathrm{a}} \pm 0.81$ & $5.1^{\mathrm{a}} \pm 1.49$ \\
M3 & $136.5^{\mathrm{bd}} \pm 4.84$ & $4.1^{\mathrm{a}} \pm 0.40$ & $9.1^{\mathrm{a}} \pm 0.68$ & $5.2^{\mathrm{a}} \pm 0.95$ \\
M4 & $146.8^{\mathrm{cde}} \pm 4.21$ & $4.8^{\mathrm{a}} \pm 0.52$ & $9.8^{\mathrm{a}} \pm 0.63$ & $5.9^{\mathrm{a}} \pm 1.83$ \\
\hline
\end{tabular}

*Means followed by different letters within column are significantly different $(P<0.05$; Tukey test). M0: oestrus; M1: 25 days after the last natural or artificial insemination; M2: 45 days after the last natural or artificial insemination; M3: 60 days after the last natural or artificial insemination; M4: 15 days after delivery. Reference values: $1.135-147 \mathrm{mg} / \mathrm{dL} ; 2.3 .5-5.0 \mathrm{mEq} / \mathrm{L} ; 3.8 .8-10.3 \mathrm{mg} / \mathrm{dL} ; 4.2 .5-5.0 \mathrm{mg} / \mathrm{dL}[6]$.

Table 2. Mean values and standard deviation (SD) of electrocardiographic parameters of six bitches at different experimental times during oestrus, pregnancy and the puerperal phase.

\begin{tabular}{cccccc}
\hline \multirow{2}{*}{ Parameter } & \multicolumn{5}{c}{ Moments } \\
\cline { 2 - 6 } & M0 & M1 & M2 & M3 & M4 \\
\hline $\mathrm{P}(\mathrm{mV})$ & $0.26^{\mathrm{a}} \pm 0.08$ & $0.14^{\mathrm{a}} \pm 0.04$ & $0.16^{\mathrm{a}} \pm 0.04$ & $0.16^{\mathrm{a}} \pm 0.07$ & $0.13^{\mathrm{a}} \pm 0.04$ \\
$\mathrm{P}(\mathrm{ms})$ & $56.0^{\mathrm{a}} \pm 5.86$ & $46.67^{\mathrm{a}} \pm 6.15$ & $45.33^{\mathrm{a}} \pm 6.18$ & $42.67^{\mathrm{a}} \pm 18.93$ & $46.67^{\mathrm{a}} \pm 2.94$ \\
$\mathrm{P}-\mathrm{R}(\mathrm{ms})$ & $87.83^{\mathrm{a}} \pm 16.36$ & $92.5^{\mathrm{a}} \pm 22.39$ & $83.0^{\mathrm{a}} \pm 16.60$ & $91.33^{\mathrm{a}} \pm 20.04$ & $81.33^{\mathrm{a}} \pm 18.87$ \\
$\mathrm{R}(\mathrm{mV})$ & $0.83^{\mathrm{a}} \pm 0.52$ & $0.85^{\mathrm{a}} \pm 0.54$ & $0.72^{\mathrm{a}} \pm 0.38$ & $0.75^{\mathrm{a}} \pm 0.33$ & $0.73^{\mathrm{a}} \pm 0.41$ \\
$\mathrm{Q}(\mathrm{mV})$ & $0.18^{\mathrm{a}} \pm 0.23$ & $0.28^{\mathrm{a}} \pm 0.37$ & $0.22^{\mathrm{a}} \pm 0.29$ & $0.20^{\mathrm{a}} \pm 0.30$ & $0.22^{\mathrm{a}} \pm 0.28$ \\
$\mathrm{QRS}(\mathrm{ms})$ & $64.66^{\mathrm{a}} \pm 9.91$ & $57.5^{\mathrm{a}} \pm 13.08$ & $58.67^{\mathrm{a}} \pm 8.52$ & $55.66^{\mathrm{a}} \pm 8.28$ & $64.33^{\mathrm{a}} \pm 6.83$ \\
$\mathrm{~T}(\mathrm{mV})$ & $57.5^{\mathrm{a}} \pm 0.04$ & $0.22^{\mathrm{a}} \pm 0.18$ & $0.15^{\mathrm{a}} \pm 0.07$ & $0.19^{\mathrm{a}} \pm 0.09$ & $0.17^{\mathrm{a}} \pm 0.24$ \\
$\mathrm{Q}-\mathrm{T}(\mathrm{ms})$ & $58.67^{\mathrm{a}} \pm 21.10$ & $205.83^{\mathrm{a}} \pm 22.28$ & $197.33^{\mathrm{a}} \pm 26.69$ & $209.5^{\mathrm{a}} \pm 25.47$ & $210.5^{\mathrm{a}} \pm 24.13$ \\
HR(bpm) & $127.83^{\mathrm{a}} \pm 16.34$ & $114.83^{\mathrm{a}} \pm 16.37$ & $135.0^{\mathrm{a}} \pm 23.77$ & $106.33^{\mathrm{a}} \pm 14.74$ & $104.83^{\mathrm{a}} \pm 16.69$ \\
Axis (o) & $55.66^{\mathrm{o}} \pm 45.09$ & $73.83^{\mathrm{a}} \pm 37.08$ & $65.33^{\mathrm{a}} \pm 29.77$ & $95.16^{\mathrm{a}} \pm 52.44$ & $74.83^{\mathrm{a}} \pm 48.75$ \\
\hline
\end{tabular}

*Means followed by different letters in line are significantly different $(P<0.05$, Tukey test). HR: heart rate. M0: oestrus; M1: 25 days after the last natural or artificial insemination; M2: 45 days after the last natural or artificial insemination; M3: 60 days after the last natural or artificial insemination; M4: 15 days after delivery.

Table 3. Mean and standard deviation (SD) values of the echocardiographic parameters obtained from six dogs in oestrus, pregnancy and the postpartum period.

\begin{tabular}{|c|c|c|c|c|c|}
\hline \multirow{2}{*}{ Parameter } & \multicolumn{5}{|c|}{ Moments } \\
\hline & M0 & M1 & $\mathrm{M} 2$ & M3 & M4 \\
\hline IVSd (mm) & $7.66^{\mathrm{a}} \pm 1.35$ & $7.78^{a} \pm 2.10$ & $6.77^{\mathrm{a}} \pm 1.94$ & $7.77^{\mathrm{a}} \pm 2.15$ & $7.91^{\mathrm{a}} \pm 1.84$ \\
\hline LVDd (mm) & $24.24^{\mathrm{a}} \pm 7.90$ & $26.43^{\mathrm{a}} \pm 8.73$ & $24.86^{\mathrm{a}} \pm 6.75$ & $26.64^{\mathrm{a}} \pm 6.44$ & $25.30^{\mathrm{a}} \pm 7.14$ \\
\hline LVWd (mm) & $7.34^{\mathrm{a}} \pm 2.55$ & $8.0^{\mathrm{a}} \pm 2.65$ & $7.15^{\mathrm{a}} \pm 1.72$ & $6.95^{\mathrm{a}} \pm 2.17$ & $8.25^{\mathrm{a}} \pm 4.01$ \\
\hline IVSs (mm) & $11.60^{\mathrm{a}} \pm 2.65$ & $10.97^{\mathrm{a}} \pm 2.8$ & $10.29^{a} \pm 1.50$ & $11.66^{\mathrm{a}} \pm 2.25$ & $11.95^{\mathrm{a}} \pm 3.70$ \\
\hline LVDs (mm) & $15.15^{\mathrm{a}} \pm 6.61$ & $17.58^{\mathrm{a}} \pm 7.8$ & $15.99^{a} \pm 6.68$ & $17.03^{\mathrm{a}} \pm 6.31$ & $17.02^{\mathrm{a}} \pm 7.73$ \\
\hline LVWs (mm) & $10.40^{\mathrm{a}} \pm 2.57$ & $10.58^{\mathrm{a}} \pm 2.86$ & $10.05^{\mathrm{a}} \pm 2.38$ & $10.16^{\mathrm{a}} \pm 2.35$ & $13.42^{\mathrm{a}} \pm 8.91$ \\
\hline $\mathrm{EF}(\%)$ & $70.94^{a} \pm 11.78$ & $65.44^{\mathrm{a}} \pm 14.38$ & $69.61^{\mathrm{a}} \pm 14.72$ & $68.66^{\mathrm{a}} \pm 11.93$ & $65.80^{\mathrm{a}} \pm 15.97$ \\
\hline $\mathrm{FS}(\%)$ & $42.01^{\mathrm{a}} \pm 7.59$ & $36.05^{\mathrm{a}} \pm 10.48$ & $38.76^{\mathrm{a}} \pm 10.39$ & $37.99^{\mathrm{a}} \pm 8.84$ & $40.02^{\mathrm{a}} \pm 11.94$ \\
\hline $\operatorname{EPSS}(\mathrm{mm})$ & $2.66^{\mathrm{a}} \pm 1.19$ & $3.28^{\mathrm{a}} \pm 1.02$ & $2.98^{\mathrm{a}} \pm 1.61$ & $2.54^{\mathrm{a}} \pm 1.29$ & $3.98^{\mathrm{a}} \pm 1.70$ \\
\hline Ao $(\mathrm{mm})$ & $14.72^{\mathrm{a}} \pm 5.57$ & $14.46^{\mathrm{a}} \pm 5.27$ & $14.83^{\mathrm{a}} \pm 5.95$ & $13.71^{\mathrm{a}} \pm 4.59$ & $15.16^{\mathrm{a}} \pm 4.62$ \\
\hline $\mathrm{LA}(\mathrm{mm})$ & $16.22^{\mathrm{a}} \pm 5.49$ & $17.18^{\mathrm{a}} \pm 5.95$ & $16.53^{\mathrm{a}} \pm 7.14$ & $16.01^{\mathrm{a}} \pm 5.15$ & $19.06^{\mathrm{a}} \pm 5.52$ \\
\hline $\mathrm{LA} / \mathrm{Ao}^{1}$ & $1.12^{\mathrm{a}} \pm 0.16$ & $1.20^{\mathrm{a}} \pm 0.16$ & $1.10^{\mathrm{a}} \pm 0.10$ & $1.18^{\mathrm{a}} \pm 0.20$ & $1.26^{\mathrm{a}} \pm 0.18$ \\
\hline Mitral E $(\mathrm{cm} / \mathrm{s})$ & $52.92^{\mathrm{a}} \pm 31.07$ & $47.50^{\mathrm{a}} \pm 12.65$ & $53.14^{\mathrm{a}} \pm 11.48$ & $58.82^{\mathrm{a}} \pm 23.28$ & $73.44^{\mathrm{a}} \pm 18.91$ \\
\hline Mitral A $(\mathrm{cm} / \mathrm{s})$ & $33.71^{\mathrm{a}} \pm 20.71$ & $34.57^{\mathrm{a}} \pm 9.78$ & $40.72^{a} \pm 9.87$ & $42.18^{\mathrm{a}} \pm 16.77$ & $53.07^{\mathrm{a}} \pm 17.36$ \\
\hline$E: A^{2}$ & $1.61^{\mathrm{a}} \pm 0.49$ & $1.38^{\mathrm{a}} \pm 0.11$ & $1.32^{\mathrm{a}} \pm 0.20$ & $1.42^{\mathrm{a}} \pm 0.25$ & $1.43^{\mathrm{a}} \pm 0.22$ \\
\hline $\mathrm{PA}-\operatorname{Vmax}^{3}(\mathrm{~cm} / \mathrm{s})$ & $86.27^{\mathrm{a}} \pm 41.40$ & $57.75^{\mathrm{a}} \pm 12.55$ & $78.86^{\mathrm{a}} \pm 17.05$ & $74.38^{\mathrm{a}} \pm 15.35$ & $83.26^{\mathrm{a}} \pm 20.37$ \\
\hline Ao- $\operatorname{Vmax}^{4}(\mathrm{~cm} / \mathrm{s})$ & $79.08^{\mathrm{a}} \pm 24.74$ & $45.94^{\mathrm{a}} \pm 10.46$ & $62.68^{\mathrm{a}} \pm 16.19$ & $67.15^{\mathrm{a}} \pm 17.32$ & $94.44^{\mathrm{a}} \pm 40.70$ \\
\hline
\end{tabular}

*Means followed by different letters within column, differ statistically $(P<0.05$, Tukey test). M0: oestrus; M1: 25 days after the last natural or artificial insemination; M2: 45 days after the last natural or artificial insemination; M3: 60 days after the last natural or artificial insemination; M4: 15 days after delivery; IVSd: interventricular septum thickness in diastole; LVDd: diameter of the left ventricle in diastole; LVWd: thickness of the left ventricular wall in diastole; IVSs: interventricular septum thickness in systole; LVDs: diameter of the left ventricle in systole; PVEs: thickness of the left ventricular wall in systole; EF: ejection fraction; FS: fractional shortening; EPSS: mitral valve E point-septal separation; Ao - aorta; LA- left atrium; LA/Ao - relationship between left atrium and aortic root; E:A - relationship between mitral E-wave and A-wave; PA-Vmax - maximum velocity of pulmonary flow; Ao-Vmax - maximum velocity of aortic flow. Reference values: 1 . LA/Ao: $0.86-1.5 ; 2$. E:A: $0.92-2.27 ; 3$. PA-Vmax: $125 \pm 26 \mathrm{~cm} / \mathrm{s} ; 4$. Ao-Vmax: $157 \pm 33 \mathrm{~cm} / \mathrm{s}$. 


\section{DISCUSSION}

The mean of $\mathrm{Na}$ concentration showed a variation between times. The reduction observed in $\mathrm{Na}$ can occur by salt depletion, by dilutional or metabolic mechanisms, once the release control of the anti-diuretic hormone (ADH) undergoes the influence of catecholamines and prostaglandins released during pregnancy, in addition to angiotensin II and other factors [17]. In contrast, the elevation in Na concentration could occur as a result of fluid and electrolyte retention by kidneys during gestation [11].

The kidneys retain $\mathrm{Na}, \mathrm{P}$ and $\mathrm{Ca}$, causing increased fluid retention producing a $75 \%$ rise in extracellular fluid volume when compared with nongestational and physiological conditions [19]. This process stimulates aldosterone production, through the renin-angiotensin system [14]. Concomitantly, in the early stages of pregnancy effective renal plasma flow is lower in order to minimize sodium loss, glomerular filtration rate increases in line with the relaxation of the afferent and efferent arterioles of the kidneys, and more fluid is retained than sodium; although the plasma concentration of this electrolyte normalizes the pregnancy progresses [19].

In the present study, the absence of electrocardiographic changes may be justified by the stability of mean serum potassium concentrations. The literature suggests that the electrocardiographic changes found during gestation in bitches may be associated with electrolyte abnormalities, especially serum K [4,9].

The observed change in the cardiac axis is consistent with the studies of Gowda et al. [12] and Blanco et al. [4], who reported that the distension of the gravid uterus can cause compression of the adjacent organs, leading to diaphragmatic compression and consequent repositioning of the thoracic structures.

Although there was no statistical difference in HR, other studies findings reported an increased HR from the 40th to 60th day of gestation and related this change to increased circulating volume and sympathetic tone [1]. The absence of significant change in this study can be explained due to the period in which the data collection was performed. Abbot [1] found an increase in HR five days before the expected calving time, demonstrating the maximum cardiac activity in this gestational phase, whereas in the present study, data were analyzed at 45 days of gestation, being therefore prior to the period of greatest HR.
Although there was no statistical difference in SBP, the body develops compensatory and adaptive mechanisms in the physiological stress of pregnancy, causing hypertension or hypotension [1]. The increased prolactin $23 \mathrm{kDa}$ isoform and oestrogen can reduce the SBP as the pregnancy progresses. However, the presence of the $14 \mathrm{kDa}$ isoform, that results from protein cleavage, is related to the occurrence of gestational hypertension, as detected in hypertensive pregnant women [15]. The occurrence of different prolactin isoforms and it's cleavage has also been observed in bitches, generating particles with different molecular profiles and bioactivity, suggesting that a similar mechanism may occur in pregnant females [10].

As showed in our results, there was a tendency to SBP reduction, that is directly influenced by peripheral vascular resistance and cardiac output [5]. During the gestation, there is a $40 \%$ increase in cardiac output in women, while in pregnant bitches, an increase of $23 \%$ is suggested as a way of responding to increased circulating blood volume [2]. To balance this out, the pregnant uterus acts to lower the pressure of the vascular system, causing a significant decrease in vascular resistance and consequent physiological reduction in SBP [3].

Although the echocardiographic findings did not show changes, it is suggested that there are changes related to increased blood volume in pregnancy to provide an appropriate blood flow to the conceptus $[1,5]$. Some undetermined aspect of pregnancy in women, possibly hormonal, may be responsible for alterations in intrinsic myocardial properties independent of the associated hemodynamic changes related to the preload and afterload shifts [16].

Dogs have been presented with atrial enlargement [1] and increased thickening of cardiac walls and large LVDd, consistent with eccentric hypertrophy [5]. Although the SF was not modified between times in this study, reports showed increased SF in late pregnancy, which was consistent with an increase in stroke volume or significant decrease in end-systolic dimension $[1,5]$. In this study, the echocardiographic exam did not show changes in LVD dimension and no other evidence of increased blood volume, resulting in a SF unchanged. The diastolic function, determined assessing mitral flow, was considered unchanged, as showed by Abbott [1] and Eghbali et al. [9]. 
Among the limitations of this study, one can cite the difficulty in obtaining a satisfactory number of animals and the variability among dog breeds, which produces heterogeneous data. One should also consider the difficulty in obtaining animals eligible to participate in such a study as well as cooperative owners.

\section{CONCLUSION}

Pregnancy and the postpartum period in dogs do not cause changes in electrolytes levels, systemic SBP values, echocardiographic and electrocardiographic parameters as compared to values obtained during oestrus.

\section{MANUFACTURERS}

${ }^{1}$ TEB - Tecnologia Eletrônica Brasileira. São Paulo, SP, Brazil. ${ }^{2}$ Esaote Brasil. São Paulo, SP, Brazil.

${ }^{3}$ Medmega Indústria de Equipamentos Médicos. São Paulo, SP, Brazil.

Ethical approval. This study was approved by the Board of Ethics in Animal Use at the Federal University of Espírito Santo (056/2012) and it was carried out in accordance with the U.K. Animals (Scientific Procedures) Act, 1986 and associated guidelines, EU Directive 2010/63/EU for animal experiments.

Declaration of interest. The authors report no conflicts of interest. The authors alone are responsible for the content and writing of the paper.

\section{REFERENCES}

1 Abbott J.A. 2010. The effect of pregnancy on echocardiographic variables in healthy bitches. Journal of Veterinary Cardiology: The Official Journal of the European Society of Veterinary Cardiology. 12(2): 123-128.

2 Almeida V.T., Uscategui R.A.R., Silva P.D.A., Avante M.L., Simões A.P.R. \& Vicente W.R.R. 2017. Hemodynamic gestational adaptation in bitches. Ciência Rural. 47(7): 1-7.

3 Barra S., Cachulo M.D.C., Providência R. \& Leitão-Marques A. 2012. Hypertension in pregnancy: The current state of the art. Revista Portuguesa de Cardiologia (English Edition). 31(6): 425-432.

4 Blanco P.G., Batista P.R., Re N.E., Mattioli G.A., Arias D.O. \& Gobello C. 2012. Electrocardiographic changes in normal and abnormal canine pregnancy. Reproduction in Domestic Animals. 47(2): 252-256.

5 Blanco P.G., Tórtora M., Rodríguez R., Arias D.O. \& Gobello C. 2011. Ultrasonographic assessment of maternal cardiac function and peripheral circulation during normal gestation in dogs. Veterinary Journal. 190(1): 154-159.

6 Bonagura J.D. 2000. Kirk's Current Veterinary Therapy XIII: Small Animal Practice. 13rd edn. Philadelphia: W.B. Saunders, 1214p.

7 Boon J.A. 2011. Veterinary echocardiography. Philadelphia: Wiley-Blackwell, 610p.

8 D’Amico E.J., Neilands T.B. \& Zambarano R. 2001. Power analysis for multivariate and repeated measures designs: A flexible approach using the SPSS MANOVA procedure. Behavior Research Methods, Instruments, \& Computers. 33(4): 479-484.

9 Eghbali M., Deva R., Alioua A., Minosyan T.Y., Ruan H., Wang Y., Toro L. \& Stefani E. 2005. Molecular and functional signature of heart hypertrophy during pregnancy. Circulation Research. 96(11): 1208-1216.

10 Gobello C., Colombani M., Scaglia H., de La Sota R.L. \& Goya R.G. 2001. Heterogeneity of circulating prolactin in the bitch. Reproduction Nutrition Development. 41(6): 505-511.

11 Gordon M.C. 2002. Maternal physiology in pregnancy. In: Gabbe S.G., Niebyl J.R., Galan H.L., Jauniaux E.R.M., Landon M.B., Simpson J.L. \& D.A. Driscoll (Eds). Obstetrics: Normal and Problem Pregnancies. 6th edn. New York: Churchill Livingstone, pp.42-65.

12 Gowda R.M., Khan I.A., Mehta N.J., Vasavada B.C. \& Sacchi T.J. 2003. Cardiac arrhythmias in pregnancy: clinical and therapeutic considerations. International Journal of Cardiology. 88(2-3): 129-133.

13 Hameed A.B. \& Sklansky M.S. 2007. Pregnancy: maternal and fetal heart disease. Current Problems in Cardiology. 32(8): 419-494.

14 Longo L.D. 1983. Maternal blood volume and cardiac output during pregnancy: a hypothesis of endocrinologic control. American Journal of Physiology - Regulatory, Integrative and Comparative Physiology. 245(5): R720-729.

15 Masumoto A., Masuyama H., Takamoto N., Akahori Y. \& Hiramatsu Y. 2010. Expression of antiangiogenic prolactin fragments in the placentas of women with pregnancy induced hypertension. Acta Medica Okayama. 64(4): 249-255.

16 Mone S.M., Sanders S.P. \& Colan S.D. 1996. Control Mechanisms for Physiological Hypertrophy of Pregnancy. Circulation. 94(4): 667-672. 
17 Naves L.A., Vilar L., Costa A.C.F., Domingues L. \& Casulari L.A. 2003. Distúrbios na secreção e ação do hormônio antidiurético. Arquivos Brasileiros de Endocrinologia \& Metabologia. 47(4): 467-481.

18 Ouzounian J.G. \& Elkayam U. 2012. Physiologic Changes During Normal Pregnancy and Delivery. Cardiology Clinics. 30(3): 317-329.

19 Prestes N.C. \& Landim-Alvarenga F.C. 2017. Obstetrícia Veterinária. 2.ed. Rio de Janeiro: Guanabara Koogan, $236 \mathrm{p}$.

20 Tilley L.P. \& Goodwin J.K. 2002. Manual of Canine and Feline Cardiology. 3rd edn. Philadelphia: W.B. Saunders, $464 p$. 